\title{
Effects of Oxytocin and Carbetocin on Haemostatic Variables in Pregnant Women after Cesarean Section
}

\author{
Testa $\mathrm{S}^{*}$, Paoletti $\mathrm{O}^{1}$, Dellanoce $\mathrm{C}^{1}$, Bassi $\mathrm{L}^{1}$, Zimmermann $\mathrm{A}^{1}$, Morandini $\mathrm{R}^{1}$, Tala $\mathrm{M}^{1}$, Catalano $\mathrm{F}^{1}$, \\ Mammoliti $\mathrm{D}^{2}$ and Riccardi $\mathrm{A}^{2}$
}

${ }^{1}$ Haemostasis and Thrombosis Center, Department of Laboratory Medicine, AO Istituti Ospitalieri, Cremona, Italy

${ }^{2}$ Obstetrics and Gynaecology Division, AO Istituti Ospitalieri, Cremona, Italy

${ }^{*}$ Corresponding author: Testa S, MD, Hemostasis and Thrombosis Center, AO Istituti Ospitalieri, Viale Concordia 1, 26100 Cremona, Italy, Fax: +390372405457, Tel: +390372405453, E-mail: s.testa@ospedale. cremona.it

Citation: Testa S, Paoletti O, Dellanoce C, Bassi L, Zimmermann A, et al. (2015) Effects of Oxytocin and Carbetocin on Haemostatic Variables in Pregnant Women after Cesarean Section. J Gynecol Res 1(2): 202. doi: 10.15744/2454-3284.1.202

Received Date: July 08, 2015 Accepted Date: July 29, 2015 Published Date: July 31, 2015

\begin{abstract}
Background: Uterine atony is the first cause of haemorrhage at delivery. To prevent post partum major bleeding uterotonic prophylactic drugs are commonly used after caesarean section. Few studies showed an haemostatic activation after oxytocin infusion while no data are available on carbetocin.

Aim: Our study aimed to evaluate if two uterotonic agents -carbetocin and oxytocin- provoke a different activation of the coagulation system in a clinical condition already known to be associated with significant changes of haemostasis. Moreover, the incidence of bleeding and thromboembolic events were evaluated.

Method: 50 consecutive women undergoing elective cesarean section, without previous bleeding or thrombotic events were enrolled. 25 women were treated with a standard 2 hours oxytocin IV infusion (10IU) and 25 women with carbetocin $100 \mu$ gr IV. Blood samples for coagulation profile (PT, aPTT, vWF:Ag, D-Dimer), blood cell count were collected before delivery (T0), 1 hour (T1) and 24 hours (T2) after drug infusion. We also studied thrombin generation, as expression of the balance between hyper- and hypo-coagulability, to obtain informations about the haemostatic assessment and its modifications in the two study groups.

Results: No major bleeding and thromboembolic events were observed in the two patient groups. Blood cell count, coagulation screening test didn't show significant differences between the two study treatments. An increase of thrombin generation was observed in carbetocin group, without, however, reaching a statistical significance.

Conclusion: This observational study shows a similar action of carbetocin compared to oxytocin on haemostatic system. Even if additional trials are necessary to confirm these preliminary data, this study suggests that carbetocin could be as safe as oxytocin in term of haemostatic action on patients already known to be at risk not only for bleeding but also for thromboembolic events in the postpartum and puerperium.
\end{abstract}

Keywords: Carbetocin; Oxytocin; Cesarean section; Uterotonic agents; Coagulation test; Thrombin generation test

\section{Introduction}

Postpartum haemorrhage (PPH) is the major cause of maternal morbidity and mortality [1]. Primary PPH is defined as a blood loss more than $500 \mathrm{ml}$ after vaginal delivery and more than $1000 \mathrm{ml}$ after caesarean section, occurring within the 24 hours following birth [1]. Even if multiple PPH predisposing factors are well known, such as a previous PPH, pre-eclampsia, coagulation defects, multiple gestation and caesarean section, in nearly one-third of cases no risk factors are identified [2]. However, uterine atony is the first cause of haemorrhage at delivery [3].

To prevent post partum major bleeding different strategies are adopted and many uterotonic prophylactic drugs are commonly used after caesarean section [4,5]. Oxytocin, a peptide hormone chemically synthesized in a biologically active form, is currently used as uterotonic agent of first choice, showing a good safety profile and decreasing PPH incidence of about 40\% [6]. On the other hand a significant limitation for its clinical use is represented by its short half-life (4-10 min), that requires continuous intravenous infusion or multiple intramuscular injections. To improve drug management carbetocin, another uterotonic agent, has been introduced in clinical practice. Carbetocin is a longer acting uterotonic agent, with a half-life of 40 min, rapid onset of action, prolonged efficacy (about 1 hour) and similar safety profile [7]. 
Several studies have compared efficacy and safety of both uterotonic agents [7-13]. A recent Cochrane review of published randomized trial showed no significant clinical differences in term of PPH incidence but carbetocin demonstrated a reduction in the need for additional uterotonic requirements [14].

Oxytocin, as syntethic hormone, has multiple central and peripheral actions [15]. It acts on human reproductive system also inducing uterine myometrial contractions to favour labour and delivery and shows haemostatic changes on the fibrinolytic system, on platelet aggregation and on coagulation factor activity [16].

Haemostatic changes during pregnancy and puerperium have been well described [17], but very few observations, limited on oxytocin, are available about the effect on the coagulation system at delivery $[18,19]$. Recently, two different studies showed a dose-dependent action on the activation of the haemostatic system, measured using tromboelastography, after oxytocin infusion $[16,20]$. To date no data are available on carbetocin haemostatic effects in comparison with oxytocin and possible differencies on the coagulation system between the two drugs cannot be excluded "a priori" also considering the more prolonged uterotonic action of carbetocin.

To evaluate the haemostatic assessment, in addition to the common coagulation test, recently the thrombin generation test (TGT) has been proposed as global test that measure the kinetic of clot formation and expresses the whole plasmatic balance between hyper- and hypocoagulability [21]. TGT evaluates the whole kinetic of thrombin generation both during the initial phase of thrombin formation as during the phase of thrombin inactivation. Compared to the common coagulation test, such as prothrombin time (PT) and activated partial thromboplastin time (aPTT), that are affected by many variables, TGT is considered more reliable in term of individual haemostatic assessment and better correlated with clinical outcomes [22,23]. Higher thrombin generation has been described in woman with pre-eclampsia [24].

To assess if women treated with carbetocin or oxytocin show differences in haemostatic profile, in addition to haemoglobin measurements used to control blood loss, we evaluated coagulation screening test (PT and aPTT), von Willebrand factor (vWF:Ag) as marker of endothelial activation, D-dimer as marker of fibrin formation and thrombin generation (TGT). The incidence of bleeding and thromboembolic events were registered in the two study groups from delivery to the end of puerperium.

\section{Materials and Methods}

\section{Design}

This is a prospective, open-label, observational trial conducted during year 2012.

\section{Patients}

50 consecutive women, aged between 22-41 years, undergoing elective cesarean section, were enrolled in the study. The first 25 women were treated with oxytocin while the following 25 with carbetocin. All women gave their written informed consent to partecipate to the study. The patients' characteristics are summarized in Table 1.

\begin{tabular}{|l|c|c|}
\hline & $\begin{array}{c}\text { OXYTOCIN } \\
\text { Mean (min-max) }\end{array}$ & $\begin{array}{c}\text { CARBETOCIN } \\
\text { Mean (min-max) }\end{array}$ \\
\hline Age & $34(22-41)$ & $32(26-39)$ \\
\hline Body Mass Index $(\mathrm{Kg} / \mathrm{m} 2)$ & $29(25-35)$ & $28(23-34)$ \\
\hline Parity & $1.0(0-2)$ & $1.0(0-2)$ \\
\hline Gestational age at delivery & $39 \pm 2$ & $39 \pm 2$ \\
\hline Ethnicity & 18 caucasian & 19 caucasian \\
& 4 asian & 3 asian \\
Previous cesarean section & 3 afroamerican & 3 afroamerican \\
\hline
\end{tabular}

Table 1: Main clinical characteristics of two patient population

Exclusion criteria were: age $<18$ years, previous bleeding or thrombotic events, hypertension, pre-eclampsia, cardiac, liver or renal diseases, general anaesthesia, pregnancy-related complications (multiple gestation, placenta praevia, placental abruption).

25 women (control group) were treated with a standard 2-h oxytocin intravenous infusion (10IU), while the 25 women of the case group were treated with a single intravenous injection of $100 \mu \mathrm{gr}$ carbetocin [13]. We evaluated the incidence of major and minor bleeding and venous thromboembolism (VTE) at delivery and during puerperium through a structured follow up conducted by the Haemostasis and Thrombosis Center. Follow up included two visits at discharge and at the end of puerperium [25]. Major bleeding included haemoglobin decrease of $2 \mathrm{~g}$ per deciliter or more, transfusion of 2 or more units of red cells or whole blood, retroperitoneal or intracranial bleeding or bleeding in critical organ, bleeding associated to death. Minor bleeding were considered all clinically relevant episodes not qualified as major [26]. VTE included deep and superficial vein thrombosis, objectively diagnosed by compression ultrasound, pulmonary embolism by computed-tomography lung scan, and thrombosis at other sites (i.e., cerebral or abdominal veins) by computed-tomography, magnetic resonance or magnetic resonance angiography. 


\section{Blood samples}

Blood samples for coagulation test, TGT and blood cell count were collected just before delivery by cesarean section (T0), 1 hour (T1) and 24 hour (T2) after drug infusion. Venous blood samples, obtained with minimal stasis, were collected using $21 \mathrm{~g}$ needle into 0.109M citrate Becton Dickinson coagulation tubes (BD, USA). Blood samples were immediate centrifuged at $2000 \mathrm{~g}$ for 20 minutes and poor platelet plasma (PPP) deeply frozen and stored at $-80^{\circ}$ before analysis.

\section{Laboratory test}

Blood cell count was assessed on automated analyser XE-5000 (Sysmex, Norderstedt, Germany). All coagulation tests were performed on frozen plasma within 3 months from blood collection.

Prothrombin time ratio (PT), activated partial thromboplastin time ratio (aPTT), von Willebrand factor antigen (vWF:Ag), D-dimer (DD) were performed on STA-R (Stago, France) using Stago reagents.

TGT was performed with a full automated commercial assay (Technothrombin TGA, Technoclone, Wien, Austria) on Ceveron a instrument, (Technoclone, Wien, Austria) and lag time ( $\mathrm{min})$, peak (nM), velocity (nM/min) and endogenous thrombin potential (ETP) were evaluated. ETP results were expressed as nM.min. The activation of coagulation in TGT was obtained by adding the commercial reagent TECHNOTHROMBIN TGA RC Low (Technoclone, Wien, Austria), containing $5 \rho$ mol tissue factor (TF).

\section{Statistics}

Data were expressed as mean \pm standard deviation (SD) and tested for normal distribution. Statistical analysis was performed by using Student's t-test for continuous variables. P-value less than $0.05(\mathrm{p}<0.05)$ was considered as statistically significant. Analysis was conducted comparing the two study groups at the different time points.

\section{Results}

The study was conducted during year 2012. A total of 50 consecutive women were enrolled and assigned to oxytocin or carbetocin treatment. The two patient populations were similar for main clinical characteristics, as shown in Table 1. Major bleeding and thromboembolic events were evaluated at delivery, at hospital discharge and at the end of puerperium (6 weeks after delivery). No major events were observed in the two groups.

Haemoglobin levels, platelet count, screening coagulation test (PT, aPTT), D-dimer and vWF:Ag, at T1 and T2, were similar in the two groups (Table 2) and no statistical differences were found.

\begin{tabular}{|c|c|c|c|c|c|c|c|}
\hline \multirow{2}{*}{} & \multicolumn{3}{|c|}{ OXYTOCIN $(\mathbf{M} \pm$ SD) } & \multicolumn{3}{c|}{ CARBETOCIN $(\mathbf{M} \pm$ SD) } & \multirow{2}{*}{ p } \\
\cline { 2 - 7 } & T0 & T1 & T2 & T0 & T1 & T2 & \\
\hline $\mathrm{Hb}(\mathrm{g} / \mathrm{dL})$ & $11.3 \pm 1.33$ & $10.3 \pm 1.58$ & $10.2 \pm 1.25$ & $11.1 \pm 0.93$ & $11.1 \pm 1.23$ & $10.4 \pm 1.38$ & n.s. \\
\hline PLTs $(\mathrm{n} / \mathrm{mmc})$ & $218 \pm 47.8$ & $221 \pm 45.07$ & $252 \pm 42.16$ & $229 \pm 46.2$ & $226 \pm 44.8$ & $256 \pm 45.3$ & n.s. \\
\hline aPTT (Ratio) & $0.99 \pm 0.05$ & $1.0 \pm 0.07$ & $1.05 \pm 0.07$ & $0.94 \pm 0.08$ & $0.89 \pm 0.10$ & $1.02 \pm 0.10$ & n.s. \\
\hline PT (Ratio) & $0.98 \pm 0.06$ & $1.04 \pm 0.08$ & $0.99 \pm 0.06$ & $0.95 \pm 0.06$ & $1.0 \pm 0.05$ & $0.96 \pm 0.06$ & n.s. \\
\hline D-Dimer (ng/mL) & $1.73 \pm 0.65$ & $1.97 \pm 0.83$ & $2.30 \pm 0.24$ & $1.98 \pm 0.35$ & $2.04 \pm 0.61$ & $2.46 \pm 0.32$ & n.s. \\
\hline vWF:Ag (U/dL) & $278 \pm 44$ & $254 \pm 53$ & $301 \pm 46$ & $265 \pm 95$ & $257 \pm 98$ & $272 \pm 77$ & n.s. \\
\hline
\end{tabular}

Table 2: Laboratory parameters in the two study groups at: pre-treatment (T0), one hour (T1) and 24 hours (T2) after uterotonic infusion ( $\mathrm{p}$ values are calculated comparing the two study groups at T1 and T2)

In respect to TGT study no differencies were observed at T0, confirming the homogeneity between the two study populations (Table 3). At T1 and T2 increases in ETP, in TGT peak and TGT velocity were observed in the carbetocin group compared with oxytocin treated patients, without, however, reaching a statistical significance.

\begin{tabular}{|c|c|c|c|c|c|c|c|}
\hline & \multicolumn{3}{|c|}{ OXYTOCIN $(\mathbf{M} \pm \mathbf{S D})$} & \multicolumn{3}{c|}{ CARBETOCIN $(\mathbf{M} \pm$ SD) } & \multirow{2}{*}{ p } \\
\hline Blood collection time & T0 & T1 & T2 & T0 & T1 & T2 & \\
\hline Time Lag (min) & $1.9 \pm 0.7$ & $2.1 \pm 1.2$ & $1.7 \pm 0.6$ & $1.8 \pm 0.8$ & $2.0 \pm 0.8$ & $1.6 \pm 0.8$ & n.s. \\
\hline Peak (nM) & $697,7 \pm 128$ & $743 \pm 138$ & $656 \pm 191$ & $675 \pm 172$ & $740 \pm 120$ & $696 \pm 200$ & n.s. \\
\hline Velocity (nM/min) & $252 \pm 106$ & $263 \pm 102$ & $248 \pm 100$ & $272 \pm 114$ & $299 \pm 129$ & $254 \pm 132$ & n.s. \\
\hline ETP (nM.min) & $3287 \pm 443$ & $3588 \pm 582$ & $3649 \pm 662$ & $3336 \pm 581$ & $3811 \pm 662$ & $3701 \pm 544$ & n.s. \\
\hline
\end{tabular}

Table 3: Thrombin generation results in the oxytocin and carbetocin study group. $\mathrm{p}$ values are calculated comparing the two study population at $\mathrm{T} 1$ and $\mathrm{T} 2$

\section{Discussion}

$\mathrm{PPH}$ is a severe partum related complication frequently associated to undetected risk factors [1] and therefore uterotonic agents are commonly adopted to prevent critical hemorrages after cesarean section. Oxytocin, a syntetic peptide hormone, is frequently used as uterotonic agent and more recently also carbetocin, an oxytocin analogue, has been introduced in clinical practice because of its longer half-life that can improve patient management. 
This study aimed to evaluate if the two uterotonic agents provoke a different activation of the haemostatic system in a clinical condition already known to be at risk not only for bleeding but also for thromboembolic events [27-29]. As known, pregnancy is a physiological condition associated with changes of the haemostatic system that globally cause an hypercoagulable condition [17] and all additional endogenous or exogenous variables should be investigated to assess possible interactions with the coagulation cascade. At our knowledge, no previous studies on a direct comparison of coagulation profile during carbetocin and oxytocin treatment in elective cesarean section have been published.

Our evaluation have shown no clinical differences in term of both early or late bleeding and thromboembolic complications between the two uterotonic agents, confirming the similar effect of the two drugs as already previously reported [14].

Laboratory test, used as marker of haemostatic impairment, didn't show differences in term of haemoglobin concentration, platelet count and coagulation profile suggesting a similar action of both carbetocin and oxytocin on the coagulation system. Moreover, to better define the global haemostatic potential and evaluate possible differencies between the two study populations, we performed TGT analyzing the different phases. The two uterotenic agents, characterized for their different half-life, showed a similar action in term of thrombin activation, with no significant increase in patients treated with carbetocin, as measured 1 hour and 24 hours after infusion. This study showed that the increased and prolonged carbetocin uterotonic activity, compared with oxytocin as recently demonstrated [10], is not associated with a significant different activation of the coagulation system, although we observed an increasing trend in ETP, TGT peak and TGT velocity at T1 and T2.

Strengths of our study are the homogeneity of the two study groups, the quality of patient's samples and the evaluation of carbetocin effects on the haemostatic system, firstly described. However some limitations deserve to be addressed. First our study wasn't a double blind randomized study and we didn't include a no treated control group. Moreover, pregnancy and delivery are conditions associated to main haemostatic changes and, consequently, we cannot clearly distinguish the drug effects on haemostasis from physiological variations at delivery and in the immediate post-partum period after cesarean section. However we highlighted a slight, but not significant, increase in the hypercoagulable response in carbetocin group compared with oxytocin.

\section{Conclusion}

In conclusion, even if large and prospective trial are necessary to confirm these preliminary data, this observational study suggests that carbetocin acts similarly as oxytocin in term of haemostatic action on patients already known to be at risk not only for bleeding but also for thromboembolic events in the post-partum and puerperium.

\section{Reference}

1. World Health Organization (2009) WHO guidelines for the management of postpartum haemorrhage and retained placenta. WHO 1-62.

2. Sheldon WR, Bloom J, Vogel JP, Souza JP, Gullmezogluam AM, et al. (2014) Postpartum haemorrhage management, risks and maternal outcomes: findings from the World Health Organization Multicountry Survey on Maternal and Newborn Health. BJOG 121: 5-13.

3. Knight M, Callaghan WM, Berg C, Alexander S, Bouvier-Colle MH, et al. (2009) Trends in postpartum hemorrhage in high resource countries: a review and recommendations from the International Postpartum Hemorrhage Collaborative Group. BMC Pregnancy Childbirth 9: 55.

4. Winter C, Macfarlane A, Deneux-Tharaux C, Zhang WH, Alexander S, et al. (2007) Variations in policies for management of the third stage of labour and the immediate management of postpartum haemorrhage in Europe. BJOG 114: 845-54.

5. Leduc D, Senikas V, Lalonde AB, Ballerman C, Biringer A, et al. (2009) Clinical Practice Obstetrics Committee; Society of Obstetricians and Gynaecologists of Canada. Active management of the third stage of labour: prevention and treatment of postpartum hemorrhage. J Obstet Gynaecol Can 31: 980-93.

6. Norström A, Andersson A, Vilhardt H (1990) Contractile effect of oxytocin and 1-deamino-1-carba-2-tyrosine (O-methyl)-oxytocin in myometrial tissue from non-pregnant and term pregnant women. Acta Endocrinol 122: 566-8.

7. Rath W (2009) Prevention of postpartum haemorrhage with the oxytocin analogue carbetocin. Eur J Obstet Gynecol Reprod Biol 147: 15-20.

8. Borruto F, Treisser A, Comparetto C (2008) Utilization of carbetocin for prevention of postpartum hemorrhage after cesarean section: a randomized clinical trial. Arch Gynecol Obstet 280: 707-12.

9. Holleboom CAG, van Eyck J, Koenen SV, Kreuwel IAM, Bergwerff F, et al. (2013) Carbetocin in comparison with oxytocin in several dosing regimens for the prevention of uterine atony after elective caesarean section in Netherlands. Arch Gynecol Obstet 287: 1111-7.

10. Larciprete G, Montagnoli C, Frigo M, Panetta V, Todde C, et al. (2013) Carbetocin versus Oxytocin in cesarean section with high risk post-partum haemorrage. J Prenat Med 7: 12-8.

11. Moertl MG, Friedrich S, Kraschl J, Wadsack C, Lang U, et al. (2011) Haemodynamic effects of carbetocin and oxytocin given as intravenous bolus on women undergoing caesarean delivery: a randomised trial. BJOG 118: 1349-56.

12. Attilakos G, Psaraoudakis D, Ash J, Buchanan R, Winter C, et al. (2010) Carbetocin versus oxytocin for the prevention of postpartum haemorrhage following caesarean section: the results of a double-blind randomised trial. BJOG 117: 929-36.

13. Boucher M, Nimrod CA, Tawagi GF, Meeker TA, Rennicks White RE, et al. (2004) Comparison of carbetocin and oxytocin for the prevention of postpartum hemorrhage following vaginal delivery: a double-blind randomized trial. J Obstet Gynaecol Can 26: 481-8.

14. Su LL, Chong YS, Samuel M (2012) Carbetocin for preventing postpartum haemorrhage. Cochrane Database Syst Rev 4: CD005457.

15. Thomas JS, Koh SH, Cooper GM (2007) Haemodynamic effects of oxytocin given as i.v. bolus or infusion on women undergoing Caesarean section. Br J Anaesth 98: 116-9.

16. Golparvar M, Esterabi M, Talakoub R, Saryazdi HH (2014) Evaluation of in vivo effects of Oxytocin on coagulation of parturient during cesarean delivery by thromboelastography. J Res Pharm Pract 3: 28-33.

17. Brenner B. Haemostatic changes in pregnancy. (2004) Thromb Res 114: 409-14. 
18. Briel RC, Kunz S, Kidess E (1979) Platelet function, coagulation and fibrinolysis during termination of missed abortion and missed labor by PGF2 alpha and oxytoci. Acta Obstet Gynecol Scand 58: 361-4.

19. Briel RC, Kidess E, Kunz S (1978) Changes of platelet function, coagulation and fibrinolysis during induction of labour at term by prostaglandin F2alpha and oxytocin (author's transl). Z Gebuetshilfe Perinatol 182: 238-42.

20. Butwick A, Harter S (2011) An in vitro investigation of the coagulation effects of exogenous oxytocin using thromboelastography in healthy parturients. Anesth Analg 113: 323-6.

21. Hemker HC, Beguin S (1995) Thrombin generation in plasma: its assessment via the endogenous thrombin potential. Thromb Haemost 74: $134-8$.

22. Hemker HC, Al Dieri R, De Smedt E, Béguin S (2006) Thrombin generation, a function test of the haemostatic-thrombotic system. Thromb Haemost 96: 553-61.

23. Baglin T (2005) The measurement and application of thrombin generation. Br J Haematol 130: 653-61.

24. Macey MG, Bevan S, Alam S, Verghese L, Agrawal S, et al. (2010) Platelet activation and endogenous thrombin potential in pre-eclampsia. Thromb 125: e76-81.

25. Testa S, Passamonti SM, Paoletti O, Bucciarelli P, Ronca E, et al. (2015) The "Pregnancy Health-care Program" for the prevention of venous thromboembolism in pregnancy. Intern Emerg Med 10: 129-34.

26. The Matisse Investigators (2003) Subcutaneous fondaparinux versus intravenous unfractionated heparin in the initial treatment of pulmonary embolism. $\mathrm{N}$ Engl J Med 349: 1695-702.

27. Lindqvist P, Dahlback B, Marsal K (1999) Thrombotic risk during pregnancy: a population study. Obstet Gynecol 94: 595-9.

28. Chang J, Elam-Evans LD, Berg CJ, et al. (2003) Pregnancy-related mortality surveillance-United States, 1991-1999. MMWR Surveill Summ 52: 1-8.

29. Lewis G ()2007 Confidential Enquiry into Maternal and Child Health (CEMACH). Saving Mothers' Lives: rewiewing maternal deaths to make motherhood safer 2003-2005. The Seventh Report on Confidential Enquiries into Maternal Deaths in the United Kingdom. London: CEMACH.

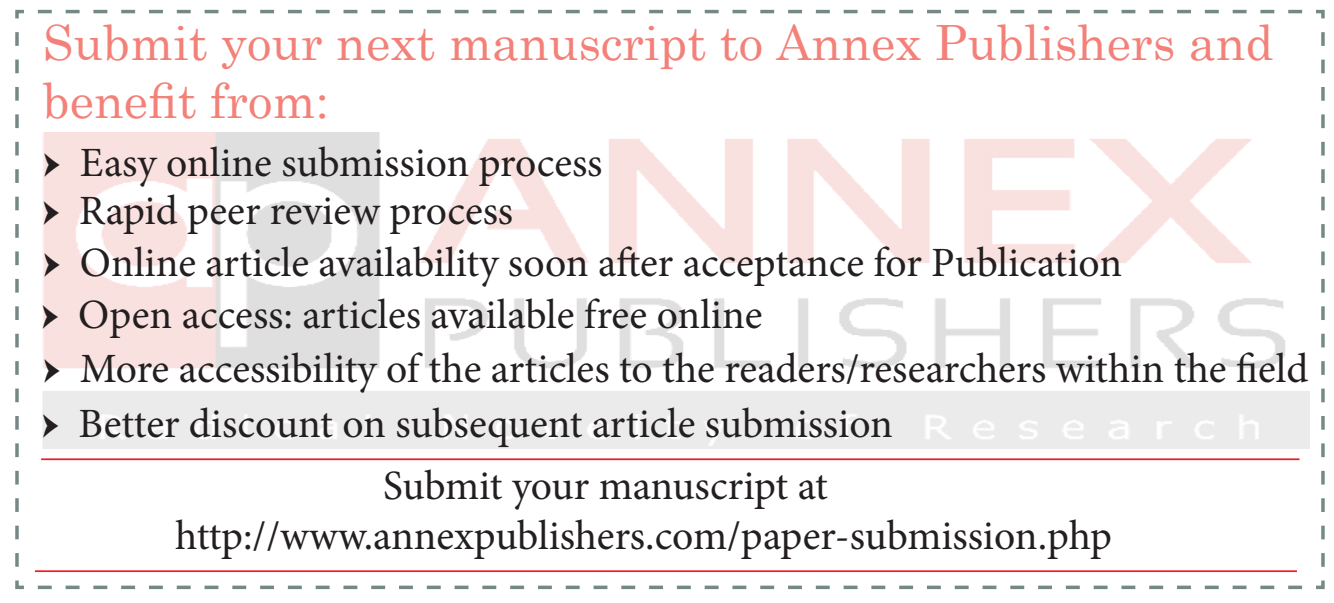

